\title{
Students' experiences with learning mergers and acquisition skills in a multi-disciplinary learning community
}

\section{Miriam Ossevoort, Daan Tavenier, Jan Riezebos}

Faculty of Economics and Business, University of Groningen, the Netherlands.

\begin{abstract}
The aim of this paper is to evaluate the implementation of an extra-curricular multi-disciplinary, multi-level Learning Community (LC) on Mergers and Acquisition (M\&A) of Small-Medium-sized Enterprises (SMEs). This LC was developed according to established guiding principles, namely the theme extends beyond the theme of the regular courses, and it should attract both BSC and MSc students of different disciplines, and enhances students' professional preparation and employability. The LC consisted of 8 meetings of 2 hours and one meeting for a whole day during a full semester. During the whole day, students played a game in which they had to purchase a company using all acquired knowledge and skills. In the guest lectures offered, students discussed different aspects of M\&A with professionals within the field. The LC is evaluated by students on e.g. the content of the $L C$, what they have learned, the social aspect and guidance, and what could be improved. Overall, the students appreciated the content and structure of the LCs, especially the game, the guest lectures, and the fact that they worked together with students of different disciplines.
\end{abstract}

Keywords: Learning Community; Higher Education; Student-centered Learning; Extra-curricular Activity; Mergers and Acquisition. 


\section{Introduction}

Owners of Small-Medium-sized Enterprises (SMEs) need support in the strategic processes associated with mergers and acquisitions of their company. In a relatively short time important and far-reaching decisions have to be taken that require knowledge from different disciplines, such as finance, strategy, operations, business administration, and legal affairs. In addition, effective managers need interpersonal skills such as negotiating skills for managerial success.

The topic of negotiation seems to be underrepresented in business school curricula. If present, buyer-supplier negotiation role-plays or games are usually used as teaching methods (Beenen \& Barbuto, 2014; Hartley \& Eboch, 2017, Page \& Mukherjee, 2007). Also at our school, the topic of negotiation is underrepresented. To introduce this topic, we have developed an extracurricular learning community on Mergers and Acquisition (M\&A) in Small Medium-sized Enterprises (SMEs).

Essential building blocks of every LC at the Faculty Economics and Business are: academically challenging topic that asks for a multi-disciplinary approach, focus on developing some specific skills, possibility to network with business practice, and selection of students based on motivation (Ossevoort \& Riezebos, 2019). Since, the content of the LC is not embedded in the formal curriculum with its rules and regulations, there is room for testing educational innovation initiatives. Being outside the curriculum, students from different levels (Bachelor and Master students) and students from different disciplines (e.g. finance, economics, business management) can participate, thereby mimicking real-life situation in M\&A processes. Since students from different backgrounds participate in this LC, peer learning allows the development of a complex way of thinking with different perspectives resulting in learning at a deeper level (Bransford et al., 2000; Lave \& Wenger, 1994). In general, LCs offer active and collaborative learning activities that binds participants together into a social entity (Wenger, 2000), where the focus of instruction shifts from the lecturer to the students.

The aim of this paper is to evaluate the implementation of the extra-curricular LC on M\&A in SMEs that is open for all BSc and MSc students at the faculty of Economics and Business. The questions we want to answer are:

1. Do students of different backgrounds participate in this LC?

2. What elements of this LC are most valued by students?

In chapter 2, the description of the LC (context and content) is given. Chapter 3 describes the data collection and analysis. The characteristics of the students as well as the outcome of the students' evaluation is given in chapter 4 . In chapter 5, the results are discussed. 


\section{Implementation of the learning community}

\subsection{Context}

The LC is part of the activities for students organized by the department FEB Careers Services to strengthen students' professional preparation and increasing graduates' employability of the Faculty of Economics and Business (FEB) of the University of Groningen, the Netherlands (Ossevoort \& Riezebos, 2019). FEB's educational portfolio consists of four broad bachelor's degree programs, twelve specialized master's degree programs, and one research master program. The topic M\&A in SMEs as such is not part of any degree program.

\subsection{Organization of the LC}

The LC is scheduled during a semester with 8 meetings of 2 hours and a whole day (to play a game). Students' time investments depend on their own ambitions.

Based on a motivation letter and an intake interview, the lecturer gives a positive or negative advice to students for participating in the LC. If positive, students are invited to the first meeting of the LC. The size of the LC is about 20 students.

The educational format of the LC is topic-based, specially designed for a targeted group with a similar academic interest, namely M\&A in SMEs (Lenning and Ebbers, 1999). The interactive meetings consist of knowledge transfer by the (guest) lecturer followed by a discussion in the whole group. During the LC, at first the lecturer is in control of what the students should learn, but during the LC the meetings become more and more studentcentered. Furthermore, students are in the lead during the day in which the game is played (see below). Since the LC is a non-credit bearing activity, after completing students receive a participation certificate.

\subsection{Content of the $L C$}

This LC teaches students the use of knowledge and tools to support the actual decisionmaking process of entrepreneurs based on the analysis of some recent M\&As of SMEs. The topics addressed are knowledge on the M\&A process, theory about negotiations, and basics of financial valuation. The skills covered are team work, interviewing, tool development, diagnostic modelling, financial valuation, and negotiation. The content of all sessions of the LC is described below.

Meeting 1 (2 hours): In this introduction meeting, the lecturer invites everyone to introduce themselves and will explain the context and content of the LC. A first discussion on the topic is started. The assignment for students to present in meeting 6 will be explained. 
Meeting 2 (2 hours): In this interactive lecture the M\&A process will be discussed using a white paper.

Meeting 3 (2 hours): In this interactive lecture, the focus is on the process of negotiation. In addition, the case used in meeting 4 is explained. The game has to be prepared in groups of three or four students. At least one of the students should have some experience with financial models to valuate a company.

Meeting 4 (whole day): This day starts with a test on negotiation style. Afterwards the game is started. The lecturer, also professional in the field of M\&A in SMEs, is together with one of the students the 'owner' of the company used in the case. They will have a strategy prepared to sell the company to a new owner. The selection of a new owner is the result of negotiations, not only based on price, but all aspects, even some 'dirty tricks', that are brought into the game. The game will consist of 4 to 5 rounds of negotiation. The students have to make a lot of decisions during the day and learn indirectly also managerial insights. At the end of the day, the 'owners' of the company will decide which group of students may purchase the company and as a result have won the game.

Meeting 5 ( 2 hours): In this meeting, the outcome of the game will be evaluated and students will reflect on the strategies, knowledge and skills used during the game.

Meeting 6 ( 2 hours): Students in small groups will present a valuation of companies in a special sector (e.g. internet industry or ICT). The content will be discussed.

Meeting 7 (2 hours): A guest lecture by a professional of an investment company will make students aware of and discuss the current practice of M\&A in SMEs.

Meeting 8 (2 hours): A guest lecture by a professional of a fast growing company will make students aware of and discuss the current practice of M\&A in SMEs.

Meeting 9 (2 hours): In the final meeting, students will present what they learned and fill out the questionnaire for evaluation purposes.

\section{Methodology}

This paper presents the results of the LC organized during three consecutive semesters of the following academic years, both semesters in 2016-2017 (LC1 and LC2) and the second semester of 2017-2018 (LC3). As of 2018-2019, the LC is organized once every academic year.

To describe if the group of participants within the LC is diverse in gender, nationality, level of education (BSc/MSc), and/or discipline, the characteristics (gender, nationality, level of education (bachelor or master), discipline) of the participants are analyzed. The LC is evaluated by the participating students by means of a questionnaire consisting of 5-point 
Likert scale items $(n=45)$ and open-ended questions $(n=13)$. The 5-point Likert scale items are partly inspired by Ciraj et al. (2010) and dealt with students' perception on (1) the content and context of the LC, (2) their improvement of skills and competencies, (3) cooperative learning and commitment to others and themselves, and (4) the social aspect of the LC. The open-ended questions deal with students' expectations, what they have learned, what kept them motivated, guidance, and what could be improved.

Students filled out the questionnaire at the last meeting of the LC on paper. The response rate was $60 \%$ in total (three LCs). Since no major differences were found between the data of the questionnaire of the three LC, all data were combined and presented as such. The mean and S.D. of the 5-point Likert scale were calculated. The qualitative data collected with the open questions were analyzed and repeated elements of different questionnaires were grouped and extracted from the data.

Table 1. Students' characteristics.

Educational level (n)

\begin{tabular}{ccccccc}
\hline & n & \% female & \% Dutch & $\begin{array}{c}\text { BSc } \\
\text { year 1/2/3 }\end{array}$ & Pre-MSc & MSc \\
\hline LC1 & 9 & $29 \%$ & $44 \%$ & $1 / 1 / 1$ & 1 & 5 \\
LC2 & 14 & $0 \%$ & $50 \%$ & $1 / 6 / 3$ & 0 & 4 \\
LC3 & 29 & $45 \%$ & $34 \%$ & $2 / 14 / 3$ & 4 & 6 \\
total & 52 & $29 \%$ & $40 \%$ & $4 / 21 / 7$ & 5 & 15 \\
\hline
\end{tabular}

\section{Results}

\subsection{Characteristics of participating students}

The characteristics of the participating students are listed in Table 1. In total 52 students participated in the three LCs of which $29 \%$ female students and 60\% international (nonDutch) students. The participants were between 18 and 31 years old (mean age $=22$ year $($ S.D. $=2.8)$ ). Most of the students follow a bachelor degree program. Most students follow a degree program in the field of finance or business economics (Table 2). In conclusion, all three LCs represented a multi-level and multi-disciplinary learning environment. 


\subsection{Students' evaluation of the LC}

The mean mark the participants gave for the LC was on a scale between 1 and 10 equal to $8.2 \pm 0.8$ (range $7-10$ ). The mean hours a week students spend on this LC was $3.7 \pm 1.0$ (range 1.5 - 6 hours). Overall, students strongly agreed that this LC as a whole worked as an effective learning environment for them (on a scale between 1 and 5, the mean score was 4.0 (S.D. 0.9)), was a good learning experience for them (mean score 4.6 (S.D. 0.6)), and they were very satisfied with this LC (mean score 4.2 (S.D. 0.6)). The students appreciated the content and context of the LC (Table 3). They perceived an increase in negotiation skills and professional skills. The students appreciated the interactive and collaborative character of the LC (Table 3). They also enjoyed working with students of different levels and disciplines (Table 3).

Table 2. The discipline of the degree programme followed by the participating students. Some students participate in multiple degree programs.

\begin{tabular}{lccc}
\hline & LC1 & LC2 & LC3 \\
\hline BSc Business Administration & 2 & - & 2 \\
BSc Economics \& Business Economics & 2 & 10 & 15 \\
BSc International Business & - & - & 3 \\
MSc Business Administration & 1 & 2 & - \\
MSc International Economics \& Business & 3 & 1 & - \\
MSc International Business and Management & - & 1 & - \\
MSc Finance & 1 & 1 & 6 \\
MSc International Financial Management & - & - & 3 \\
MSc Supply Chain Management & - & - & 1 \\
\hline
\end{tabular}

In the open-ended questions students stated that the mean reason for participating in this LC was to improve knowledge on M\&A ( $n=26)$. As the most important things learned during this LC, students mention learning about negotiation $(n=23)$, valuation $(n=10), M \& A$ processes and modelling $(\mathrm{n}=11)$, and the importance of networking and building relationships in M\&A $(n=10)$. They stated that they welcomed the cooperation with students from different levels ( $n=16)$ ("Good, I think that different levels add their own ideas and way of thinking to the LC"). Students mentioned that they learned from each other $(n=16)$ ("as everyone had their specialty, I learnt about subjects I'm weaker in from group members that were skilled"), and the different view on the topics by students of different disciplines was instructive $(n=15)$ ("I learnt a lot how finance students think and solve problems"). 
Suggestions to improve this LC were to expand the link with practice meaning more company visits and guest lectures $(n=11)$ and gaining more content knowledge $(n=4)$, such as providing homework exercises, a crash course valuation in the beginning of the LC, and learning about differences between SMEs and multi-national companies.

Table 3. Students' perceived learning and experience during the LC (mean scores on a 5- point Likert scale, range $1=$ strongly disagree to $5=$ strongly agree).

item

Mean score

(S.D.)

\section{Content and context of LC}

The information which I received about the LC was sufficient

$4.1(0.7)$

The LC was well organized

The contact with the external parties during the LC met my expectations

Cases selected for LC were appropriate

Student discussion during LC sessions addressed the objectives of the given subject

The time allotted for the LC was adequate

The reference material used for $\mathrm{LC}$ were useful and adequate

LC provided a context that helped me retaining relevant information

$4.0(0.6)$

The lecturer present during LC facilitated the whole process

The support I received form the lecturer during the LC was helpful

Participation of external business people should always be part of the LC

I could bring forward new topics in LC

The LC was academically challenging

I would recommend this LC to other students

$4.6(0.7)$

\section{Improvement of skills and competencies}

LC has facilitated my independent (self-directed) learning abilities $3.9(0.7)$

LC helped me gain skills in working with others

LC has enhanced my communication skills (e.g. writing, speaking)

LC increased my analytical skills

LC has enhanced my project-management skills 
item

Mean score

(S.D.)

\begin{tabular}{lc}
\hline LC has enhanced my negotiating skills & $4.5(0.7)$ \\
LC has enhanced my professional skills & $4.0(0.8)$ \\
\hline
\end{tabular}

\section{Cooperative learning and commitment to others and themselves}

LC has helped me generate questions that forced me to further investigate the $4.2(0.7)$ subject

LC gave me the opportunity to help others in the group understand difficult material

LC helped me better understand the subject by hearing other participants discuss it

Explaining information to others helped me better understand the subject

When working together with students in LC, I achieved more than I work alone

LC enhances good working relationships among students

LC focused on collective efforts rather than individual efforts

In the LC it was difficult getting members to actively participated in tasks

\section{The social aspect of the LC}

The atmosphere in the LC was relaxed

LC was fun

LC has helped me to socialize more

LC fostered team spirit

By participating in LC, I made new friends

I enjoyed working with students from different educational levels

I enjoyed working with student with a different background

LC has strengthened my societal awareness

LC has enhanced my intercultural competencies 


\section{Discussion and Conclusion}

We conclude that the implementation of the extra-curricular Learning Community (LC) on Mergers and Acquisition (M\&A) of Small-Medium-sized Enterprises (SMEs) that is open for all students at the Faculty of Economics and Business was a success. The LC was developed to give students the opportunity to learn about this topic in a real-life situation, using a game and working together with students of different levels and disciplines. Being extra-curricular, the LC complements the activities within the curriculum where students of the same levels and disciplines work together. Students learned from each other as well as from the (guest) lecturers who are consultants in M\&A. The results let us conclude that the contact with the professional field should absolutely be part of the LC and that the academic character can be intensified. Overall, the great commitment of the lecturer as well as the students led to a successful realization of this multi-disciplinary, multi-level extra-curricular LC on M\&A in SMEs.

\section{References}

Beenen, G., \& Barbuto, J. E. (2014). Let's make a deal: a dynamic exercise for practicing negotiation skills. Journal of education for business, 89, 149-155. doi: 10.1080/08832323.2013.794121.

Bransford, J. D., Brown, A. L., \& Cocking, P. R. (eds) (2000). How People Learn: Brain, Mind, Experience, and School. Washington: National Research Council/National Academy Press.

Ciraj, A. M., Vinod, P., \& Ramnarayan, K. (2010). Enhancing active learning in microbiology through case based learning: Experiences from an Indian medical school. Indian Journal of Pathology and Microbiolology, 53, 729-33.

Hartley, J. L., \& Eboch, K. (2017). Using a corporate partnership to enhance in a sourcing negotiation role-play. Decision Sciences Journal of Innovative Education, 15 (2), 124137. doi: $10.1111 / \mathrm{dsji} .12123$.

Lave, J., \& Wenger, E. (1994). Situated learning: legitimate peripheral participation. Cambridge: Cambridge University Press.

Lenning, O., \& Ebbers, L. (1999). The powerful potential of learning communities: Improving education for the future. ASHE-ERIC Higher Education Report, 26(6).

Ossevoort, M., \& Riezebos, J. (2019). Evaluation of learning communities: principles to guide practice. In Head'19 $5^{\text {th }}$ International Conference on Higher Education Advances (p. 1069-1077). Editorial Universitat Politecnica de Valencia. doi: 10.4995/HEAD19.2019.9255.

Page, D., \& Mukherjee, A. (2007). Promoting critical thinking skills by using negotiation exercises. Journal of Education for Business, 82(5), 251-257. doi: 10.3200/JOEB.82.5.251-257.

Wenger, E. (2000). Communities of practice and social learning systems. Organization, 7 , 225-245. doi: 10.1177/135050840072002. 